\title{
TAMING SUPER LeWIS ACIDS FOR CATALYSIS: THE FAMILY OF FERROCENE-STABILIZED Silicon CATIONS
}

\author{
Hendrik F. T. Klare, ${ }^{a}$ Kristine Müther, ${ }^{a}$ Roland Fröhlich, ${ }^{b}$ and Martin Oestreich ${ }^{\mathrm{a},{ }^{\star}}$ \\ aInstitut für Chemie, Technische Universität Berlin, Straße des 17. Juni 115, 10623 Berlin, Germany \\ ${ }^{b}$ Organisch-Chemisches Institut, Westfälische Wilhelms-Universität Münster, Corrensstraße 40, 48149 Münster, Germany \\ Email: martin.oestreich@tu-berlin.de
}

\section{Concept}

Silylium ions, that are tricoordinate silicon cations, are exceptionally strong electron pair acceptors, so strong that they react with almost any $\sigma$ and $\pi$ basic molecule..$^{[1]}$ In order to use such reactive intermediates in Lewis acid catalysis, ${ }^{[2]}$ we have designed intramolecularly stabilized silylium ions whose electron deficiency is attenuated by an adjacent, electron-rich ferrocenyl fragment. The Lewis basic iron atom tames the Lewis acidity of the silicon atom and is also intended to secure catalytic turnover.

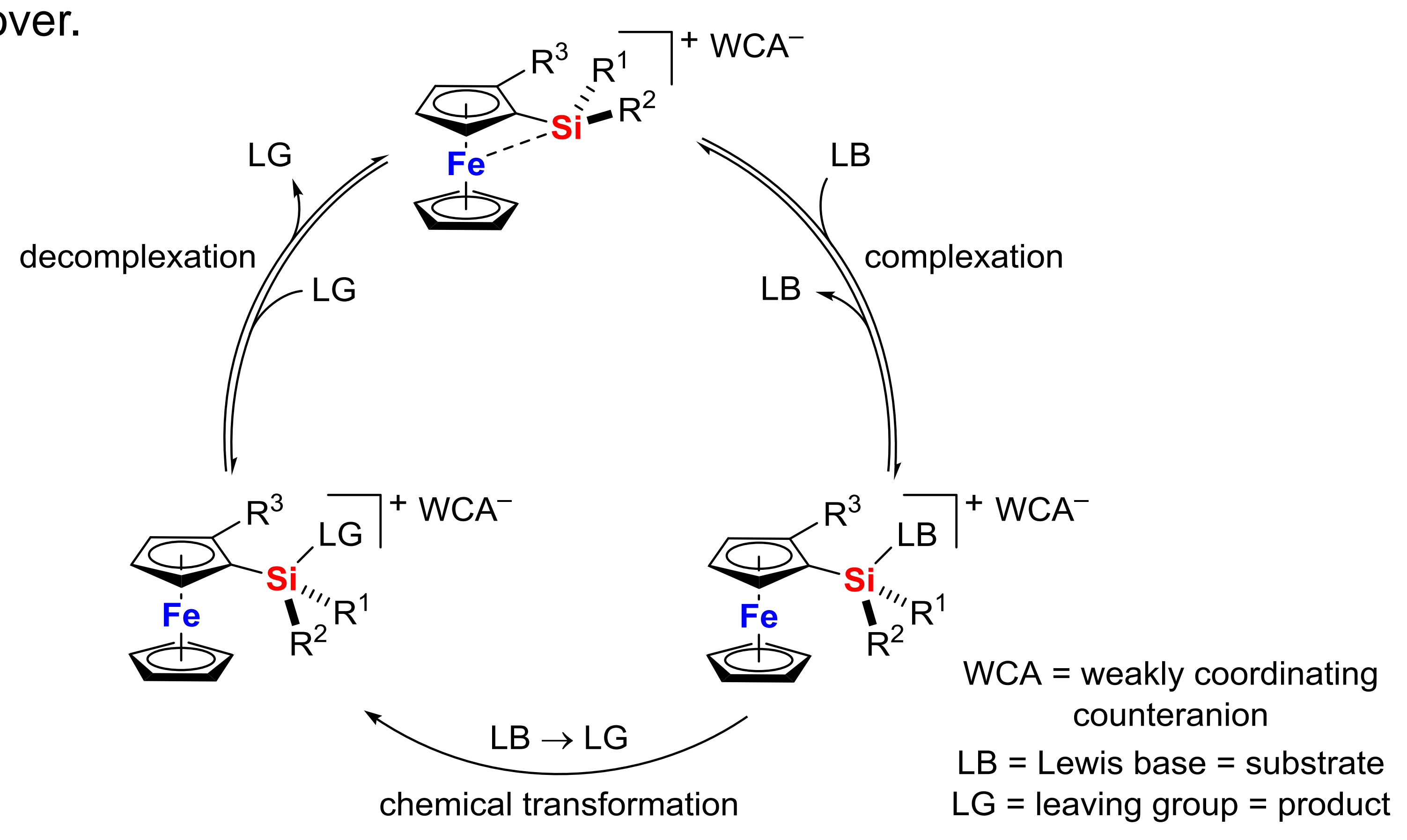

\section{Synthesis and ${ }^{29}$ Si NMR Spectroscopy}

Silylium ions are commonly prepared by hydride abstraction from the corresponding silane precursor using the trityl salt of a weakly coordinating anion. ${ }^{[3]}$ Following this strategy, we were able to synthesize a novel family of ferrocene-stabilized silicon cations with various substitution patterns at the silicon atom. ${ }^{[4]}$

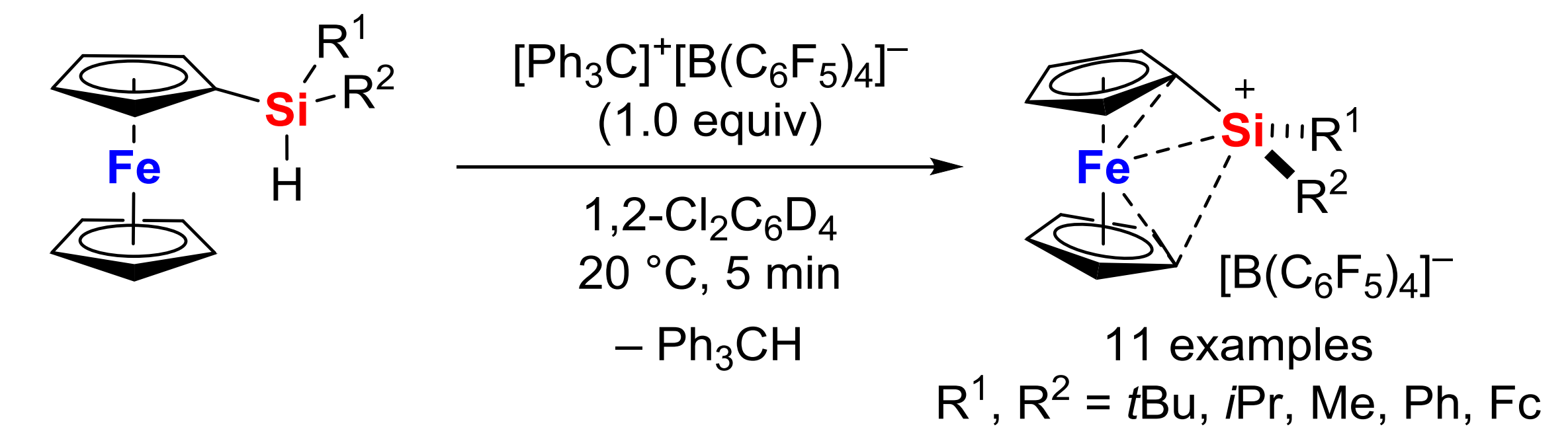

All new silicon cations were characterized by detailed NMR spectroscopy studies in solution. The ${ }^{29} \mathrm{Si} \mathrm{NMR}$ chemical shifts are strongly dependent on the electronic and steric nature of the substituents at the silicon atom. Dialkyl-substituted silicon cations show significantly more deshielded signals $(\delta=110.7-120.9 \mathrm{ppm})$ than the aryl-substituted members $(\delta=81.0-98.6 \mathrm{ppm})$, while sterically less demanding substituents lead to lower-frequency silicon shifts as a result of a more effective interaction between the ferrocene moiety and the silicon atom.

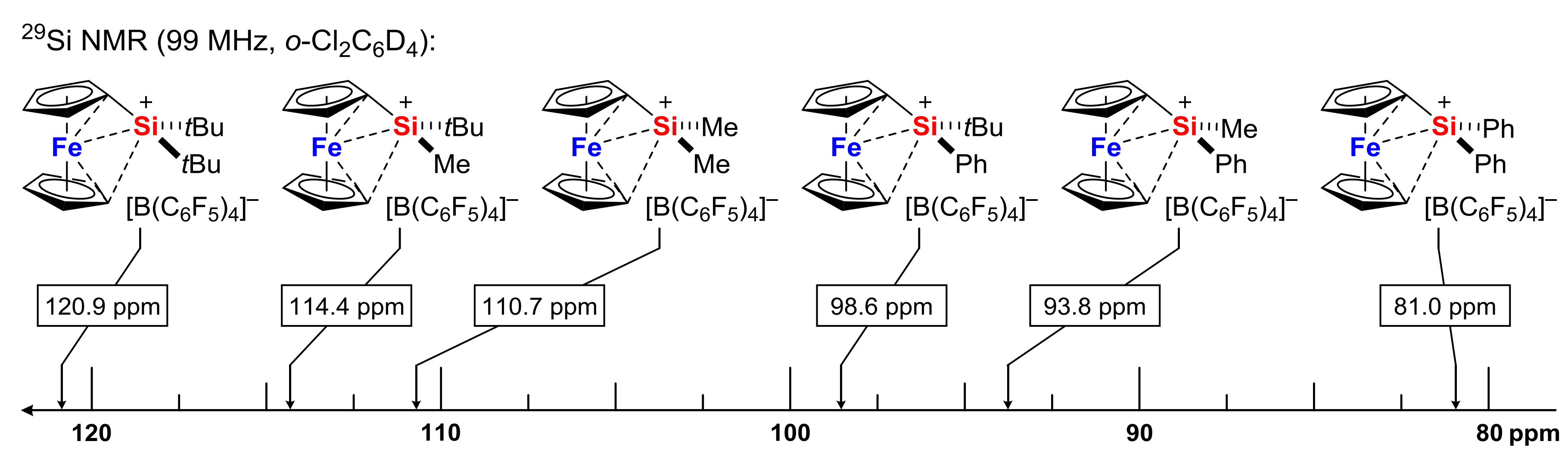

\section{Structural Characterization}

Replacement of the $\left[\mathrm{B}\left(\mathrm{C}_{6} \mathrm{~F}_{5}\right)_{3}\right]^{-}$counteranion by the closo-boranate $\left[\mathrm{B}_{12} \mathrm{Cl}_{12}\right]^{2-}$ finally allowed the successful crystallization of a ferrocene-stabilized silicon cation. ${ }^{[5]}$ The unique molecular structure reveals an unprecedented bonding motif different from its analogues. An extreme dip angle of the silicon atom toward the iron atom is explained by two three-center two-electron (3c2e) bonds through participation of both the upper and the lower aromatic rings of the ferrocene sandwich structure.
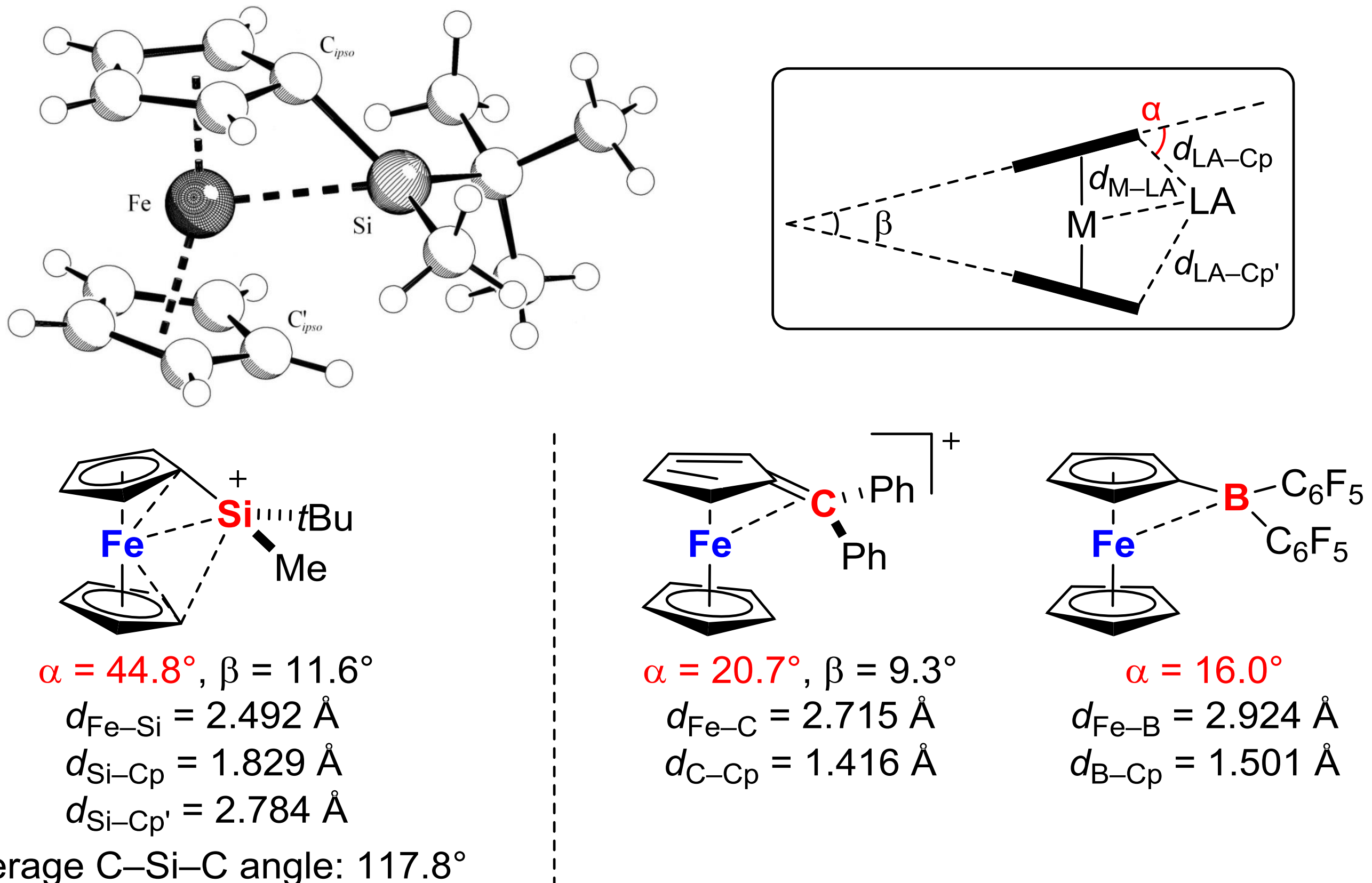

\section{Application in Lewis Acid Catalysis}

By this mode of stabilization, an almost planar geometry and a positive charge located at the silicon atom is retained, providing a highly reactive silicon Lewis acid. The tamed silicon cation catalyzes various demanding Diels-Alder reactions (1,3-cyclohexadiene is approx. 500 times less reactive than cyclopentadiene!) at low temperatures with exceptional reaction rates and selectivities. ${ }^{[6]}$

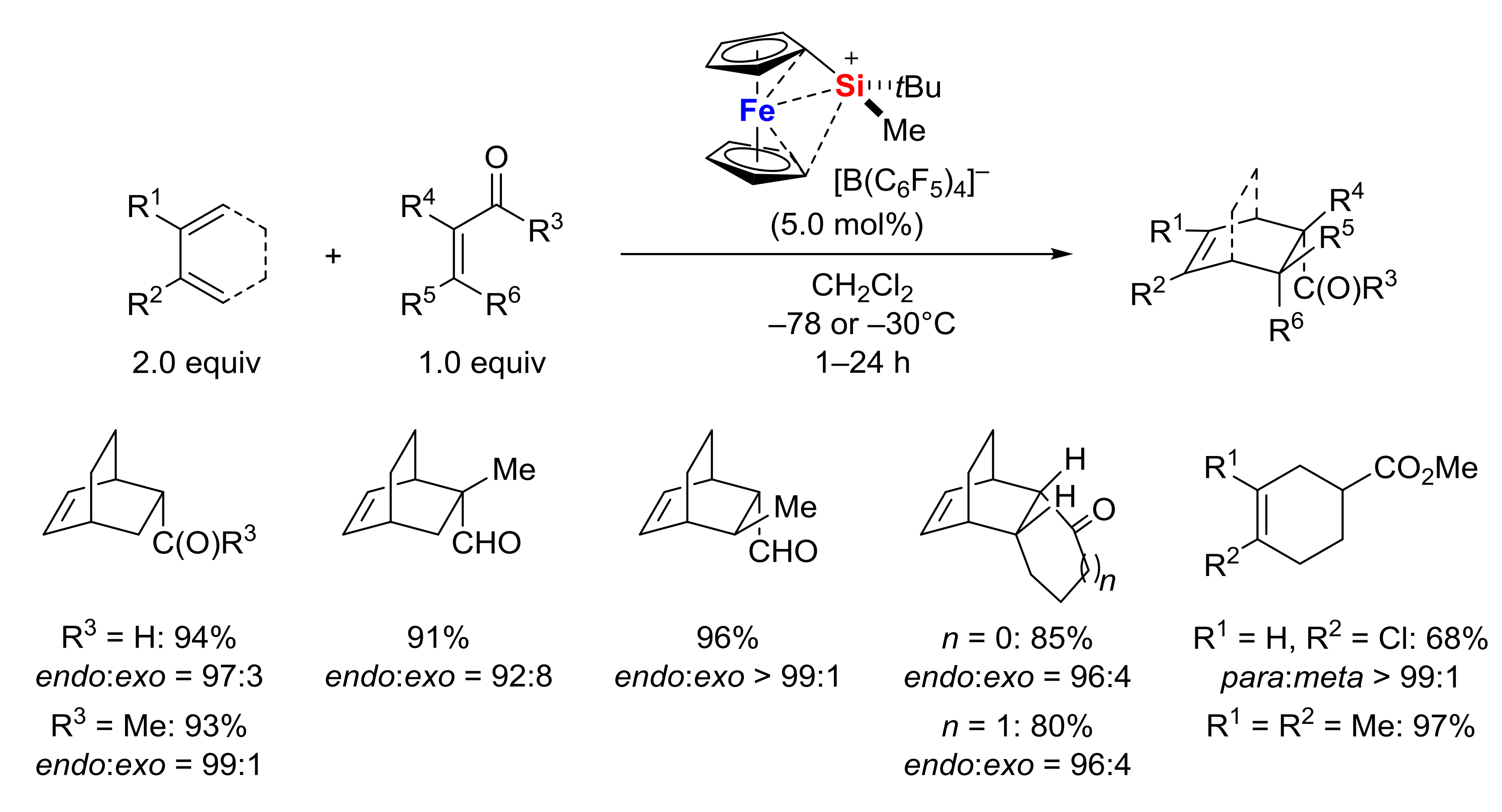

\section{Comparison with Reported Lewis Acid Catalysts}

The outstanding level of reactivity of our ferrocene-stabilized silicon cation is highlighted by a comparison with reported silicon Lewis acids. These examples also demonstrate the qualitative correlation of the ${ }^{29} \mathrm{Si} \mathrm{NMR}$ chemical shift and Lewis acid strength.

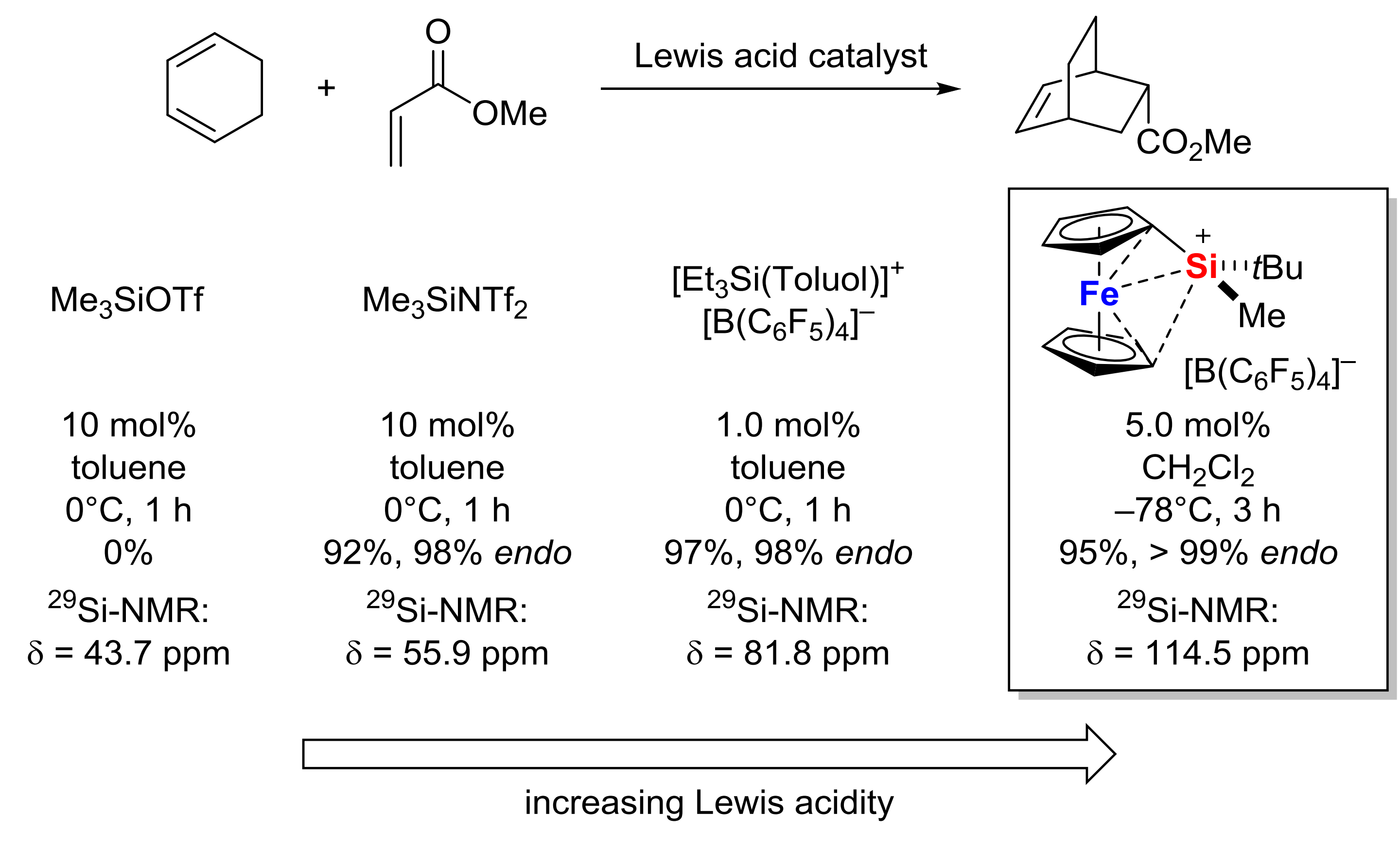

\section{Conclusion}

In summary, we accomplished the preparation and structural characterization of a new family of ferrocene-stabilized silicon cations. The intramolecular stabilizing interaction between the silicon cation and the ferrocene backbone is characterized by two three-center two-electron (3c2e) bonds through participation of both cyclopentadienyl rings. By this mode of stabilization, the positive charge is still localized at the silicon atom that also retains an almost planar configuration. The potential of our tamed silylium ion as a Lewis acid catalyst is demonstrated in challenging Diels-Alder reactions that are catalyzed in an unprecedented temperature range.

\section{Acknowledgement}

This research was supported by the Deutsche Forschungsgemeinschaft. M.O. is indebted to the Einstein Foundation (Berlin) for an endowed professorship.

\section{References}

[1] a) T. Müller in Structure and Bonding, Vol. 155 (Ed.: D. Scheschkewitz), Springer, Berlin 2014; pp. 107-162; b) T. Müller in Science of Synthesis: Knowledge Updates 2013/3 (Ed.: M. Oestreich), Thieme, Stuttgart, Germany, 2013, pp. 1-42.

[2] a) A. Schulz, A. Villinger, Angew. Chem. Int. Ed. 2012, 51, 4526-4528; b) H. F. T. Klare M. Oestreich, Dalton Trans. 2010, 39, 9176-9184.

[3] J. Y. Corey, D. Gust, K. Mislow, J. Organomet. Chem. 1975, 101, C7-C8.

[4] K. Müther, R. Fröhlich, C. Mück-Lichtenfeld, S. Grimme, M. Oestreich, J. Am. Chem. Soc 2011, 133, 12442-12444.

[5] K. Müther, P. Hrobárik, V. Hrobárikova, M. Kaupp, M. Oestreich, Chem. Eur. J. 2013, 19, 16579-16594.

[6] a) H. F. T. Klare, K. Bergander, M. Oestreich, Angew. Chem. Int. Ed. 2009, 48, 9077-9079; b) R. K. Schmidt, K. Müther, C. Mück-Lichtenfeld, S. Grimme, M. Oestreich, J. Am. Chem. Soc. 2012, 134, 4421-4428. 